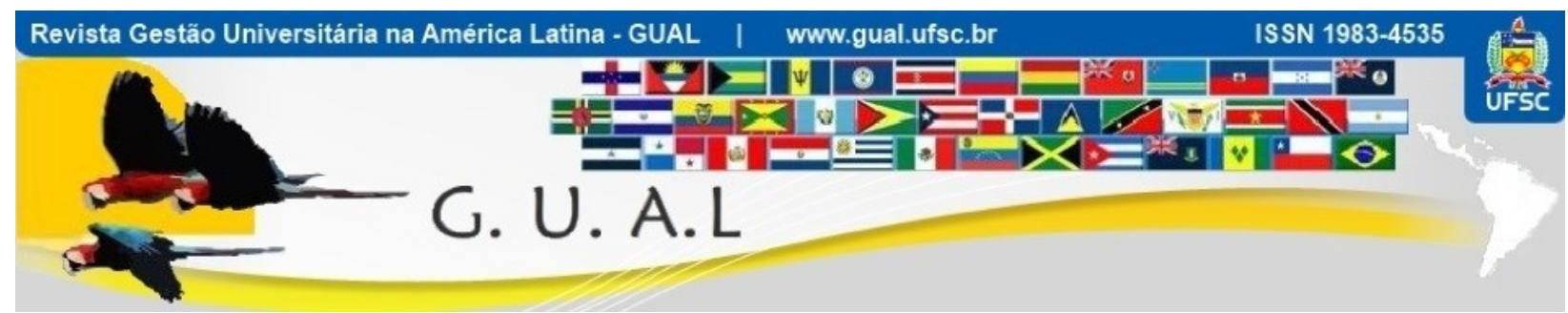

DOI: http://dx.doi.org/10.5007/1983-4535.2019v12n1p118

\title{
GESTÃO DO PLANEJAMENTO E ACOMPANHAMENTO DE ATIVIDADES DOCENTES DE UMA UNIVERSIDADE FEDERAL
}

\section{MANAGEMENT OF PLANNING AND FOLLOW-UP OF TEACHING ACTIVITIES OF A FEDERAL UNIVERSITY}

\author{
Roberta Souza Matos, Bacharel \\ https://orcid.org/0000-0003-2546-8374 \\ robertasmts@gmail.com \\ Universidade Federal de Santa Catarina | Departamento de Ciências da Administração \\ Florianópolis | Santa Catarina | Brasil \\ Irineu Manoel de Souza, Doutor \\ https://orcid.org/0000-0002-3640-0853 \\ irineu.manoel@ufsc.br \\ Universidade Federal de Santa Catarina | Programa de Pós-Graduação em Administração Universitária \\ Florianópolis | Santa Catarina | Brasil \\ Flora Moritz da Silva, Doutora \\ https://orcid.org/0000-0002-3292-4430 \\ floramds@gmail.com \\ Universidade Federal de Santa Catarina | Programa de Pós-Graduação em Administração \\ Florianópolis | Santa Catarina | Brasil \\ Gabriela Guichard de Lima Beck, Mestre \\ https://orcid.org/0000-0002-1869-2127 \\ g.beck@hotmail.com \\ Universidade Federal de Santa Catarina | Programa de Pós-Graduação em Administração \\ Florianópolis | Santa Catarina | Brasil
}

Recebido em 27/julho/2017

Aprovado em 29/outubro/2018

Publicado em 02/janeiro/2019

Sistema de Avaliação: Double Blind Review 


\title{
RESUMO
}

Os docentes do ensino superior das universidades federais desenvolvem atividades que ultrapassam o ensino em sala de aula, como por exemplo pesquisa e extensão, além de atividades administrativas. Tal amplitude denota a importância da existência de um planejamento das atividades docentes. Este artigo tem como objetivo principal analisar a gestão do sistema de Planejamento e Acompanhamento de Atividades Docentes - PAAD - de uma universidade federal. Para tanto, elaborou-se os seguintes objetivos específicos: conhecer a legislação e o sistema PAAD da universidade federal e identificar os principais desafios deste sistema. Trata-se de um estudo de caso, de caráter descritivo e natureza qualitativa, que fez uso de pesquisa bibliográfica, análise documental e entrevista semiestruturada com os responsáveis pelo sistema PAAD e com um chefe de departamento que utiliza o sistema, como instrumentos de pesquisa. Obteve-se como resultados a descrição do sistema PAAD que está estruturado para atender a Resolução $\mathrm{n}^{\circ}$ 053/CEPE/9531 de agosto de 1995, além de sugestões de melhorias para este sistema, as quais foram embasadas em relatos obtidos nas entrevistas feitas com alguns dos responsáveis pelo PAAD na UFSC.

Palavras-chave: Docentes. Gestão Universitária. Planejamento.

\begin{abstract}
Teachers of higher education at federal universities develop activities that go beyond teaching in the classroom, such as research and extension, as well as administrative activities. Such scope expose the importance of the existence of a planning of teaching activities. Thus, this article aims to analyze the management of the Planning and Monitoring of Teaching Activities - PAAD of a federal university. For that, the following specific objectives were elaborated: to know the legislation and the PAAD system of the university and to identify the main challenges of said system. This is a descriptive and qualitative case study, which made use of bibliographic research, documentary analysis and semi-structured interviews with those responsible for the PAAD system and with a department head who uses the system as research instruments. As a result, the description of the PAAD system that is structured to comply with Resolution No. 053 / CEPE / 9531 of August 1995, as well as suggestions for improvements to this system, based on the reports obtained in the interviews made with some of those responsible by PAAD at UFSC.
\end{abstract}

Keywords: Teachers. University Management. Planning. 


\section{INTRODUÇÃO}

A docência universitária vem se estabelecendo como um campo importante para a realização de pesquisas, uma vez que existem diversas lacunas que motivam investigações de gestores universitários e estudiosos da área de educação. A legislação brasileira não contempla as necessidades da formação de professores nesse nível de ensino. A Lei 9394/96, que estabelece as diretrizes nacionais de educação no Brasil, menciona apenas que a formação dos docentes do ensino superior dar-se-á preferencialmente em cursos de mestrado e doutorado, não estabelecendo a obrigatoriedade de uma formação pedagógica específica para este relevante nível de ensino. (BRASIL, 1996). Desta forma, os docentes universitários constroem suas formações por meio de cursos diversos e de suas vivências no dia a dia na sala de aula.

Para Alexandra Folle et al. (2009) a carreira docente é permeada por desafios, dilemas e conquistas que repercutem no processo de como o professor percebe-se e sente-se no ambiente de trabalho, na busca da realização pessoal e profissional. Recktenvald e Souza (2016) explicam que os docentes das instituições federais de ensino superior desenvolvem atividades em áreas indissociáveis de ensino, pesquisa e extensão, além de atividades administrativas, em diferentes regimes de contratos, que tornam as relações de trabalho complexas nas universidades, estimulando tais organizações a criar normatizações das atividades docentes, ou seja, um Planejamento e acompanhamento de atividades docentes (PAAD).

Ribeiro (2005) compreende a função de planejamento como uma das atividades indispensáveis ao processo administrativo, sendo essencial para a gestão das organizações. $\mathrm{O}$ planejamento em questão é feito de maneira autônoma pelas instituições universitárias, segundo o Art. 207 da Constituição Federal o qual trata deste tema e estabelece que as universidades gozam de autonomia didático-científica, administrativa e de gestão financeira e patrimonial, além de que devem obedecer ao princípio de indissociabilidade entre ensino, pesquisa e extensão. (BRASIL, 1988).

Considerando esse contexto, Recktenvald e Souza (2016) explicam que as universidades públicas brasileiras estabeleceram e continuam estabelecendo suas normatizações sobre as atividades docentes, envolvendo as áreas indissociáveis da educação superior: o ensino, pesquisa e extensão. Tais normativas, próprias a cada instituição, precisam respeitar aspectos de transparência, legalidade, eficiência, razoabilidade e economicidade. Contudo, os autores ressaltam que dentre as universidades públicas brasileiras, existem perfis 
diversos como instituições tradicionais e com décadas de história, até instituições novas, criadas no processo recente de interiorização da educação superior pública no Brasil.

Considerando o exposto, essa pesquisa busca compreender a gestão do sistema PAAD em uma universidade com décadas de trajetória, definindo-se a seguinte pergunta de pesquisa: como ocorre a gestão do sistema PAAD - Planejamento e Acompanhamento de Atividades Docentes na Universidade Federal de Santa Catarina?

A partir da pergunta de pesquisa, apresenta-se como objetivo geral analisar a gestão do sistema PAAD da UFSC, e como objetivos específicos: conhecer a legislação e o sistema PAAD da UFSC e identificar os principais desafios do referido sistema.

Além de tratar da carreira do docente, o presente estudo trata de expor como ocorre as funções de ensino, pesquisa, extensão e de gestão da universidade federal estudada. A indissiociabilidade das funções de ensino, pesquisa e extensão está prevista em lei, tornando importante um estudo que apresente os caminhos da gestão do PAAD de uma universidade federal, não só por referir-se aos professores universitários, mas porque interfere no desempenho de toda a comunidade universitária.

Conhecer e apresentar melhorias para a gestão do PAAD trará consequências sociais para o setor universitário, tendo em vista que influenciará em melhorias não só nas atividades docentes, mas também na gestão universitária. Para justificar esta afirmação, Borges \& Araújo (2001) destacam que as principais características da gestão universitária são fatores como um elevado profissionalismo e domínio na tarefa, que implicam em autonomia no trabalho e liberdade de fortes supervisões, ou seja, os professores escolhem o que investigar e como ensinar, o que traz influências diretas nas decisões coletivas e desenvolvem lealdades interinstitucionais.

O tema se torna relevante para a gestão universitária visto que o conhecimento e a proposição de melhorias para o PAAD ocasionarão consequências positivas para docentes, alunos, e para os gestores responsáveis pela elaboração e gestão de tal planejamento, influenciando no cotidiano da comunidade universitária como um todo. Há ainda a importância cientifica, pois é um tema novo, com poucos estudos a respeito do assunto, e, novos trabalhos ressaltando a importância da gestão do PAAD tendem a estimular novas pesquisas. O estudo é exequível, pois apesar de haver poucos estudos a respeito desse assunto, os autores possuem acesso a tais referências e oportunidade para se fazer coleta documental e entrevistas com os atores envolvidos com o referido sistema na UFSC. 


\section{GESTÃO DAS UNIVERSIDADES FEDERAIS}

Vale contextualizar a administração pública, já que as universidades federais são instituições públicas vinculadas ao Ministério da Educação. Para Pereira (2012) a administração pública pode ser entendida como uma estrutura de poder executivo, que tem missão de coordenar e implementar as politicas públicas. Apresenta-se como um conjunto de atividades diretamente destinadas à execução além de concentrar atividades consideradas de interesse público ou comuns numa coletividade ou numa organização estatal.

Bobbio (2001) ratifica tal entendimento ressaltando que na forma mais abrangente, a expressão administração pública designa o conjunto de atividades diretamente destinadas à execução das atividades ou incumbências consideradas do interesse público ou comum.

As universidades são instituições pluridisciplinares de formação dos quadros profissionais de nível superior, de pesquisa, de extensão e de domínio e cultivo do saber humano, que se caracterizam por: produção intelectual institucionalizada mediante o estudo sistemático dos temas e problemas mais relevantes, tanto do ponto de vista científico e cultural, quanto regional e nacional; um terço do corpo docente, pelo menos, com titulação acadêmica de mestrado ou doutorado; um terço do corpo docente em regime de tempo integral. (BRASIL, 1996).

Palmeiras, Sgari e Szilagyi (2015) defendem que o conceito de gestão universitária deve ser entendido como algo mais amplo do que a implantação de ações de planejamento estratégico, ou qualquer outra forma tradicional de gestão. Por tratar-se de um tipo de organização complexa, as instituições de ensino superior exigem um alto nível de especialização funcional, o que configura um processo permanente de tomada de decisões, no qual são possíveis diferentes tipos de racionalidade: política, religiosa, social e econômica. Considerando a natureza da instituição - prestadora de serviço - predomina nas decisões a racionalidade política.

Girard et al. (2010) ressaltam que as universidades cumprem papel essencial na construção de uma sociedade mais justa. São instituições de produção de conhecimento e de desenvolvimento tecnológico econômico e social. Sendo assim, é fundamental que mantenham permanentemente a preocupação em adequar as suas práticas de gestão, para o pleno cumprimento da sua missão. 


\subsection{PLANO DE ATIVIDADES DOCENTES NAS IFES}

Planejar é a ideia de realizar alguma coisa. É uma sequência de etapas que se encadeiam a fim de tornar-se um plano ou projeto. Inicialmente tem-se a análise das implicações, formulação de conceitos, criação de esboços exequíveis e de anteprojetos, até a criação do projeto definitivo. (RIBEIRO, 2005).

Vasconcelos (1999) divide o conceito em três níveis. O primeiro é o planejamento da escola que significa projeto político-pedagógico ou projeto educativo. É o plano integral da instituição apresentando marco referencial, diagnóstico e programação. O segundo nível é o planejamento curricular que é a proposta geral de aprendizagem que irá conter fundamentos da disciplina, área de estudo, desafios pedagógicos, processos de avaliação e conteúdo. Por fim o terceiro nível é denominado projeto de ensino-aprendizagem que se refere ao planejamento do professor na sala de aula, restrito ao aspecto didático subdividido em projeto de curso e plano de aula.

Considerando esta divisão, Martens, Ventura e Júnior (2013) percebem que as condições para efetuar um trabalho educacional efetivo dependem da capacidade de transformar a atividade em projeto, ou seja, um todo que se articule entre as partes para que estas possam funcionar integradas em função de objetivos.

A gestão de pessoas tem grande importância nessas instituições. Segundo Aranha e Salles (2015) uma das áreas mais emblemáticas da administração é a gestão de pessoas, pois é a partir de como se gerencia os recursos humanos da instituição que alterações importantes podem acontecer nas estratégias da organização. Essa área deve ser encarada como elemento estratégico das organizações, fonte essencial para a busca da vantagem competitiva e, consequentemente, de resultados positivos. Esse pensamento não é diferente dentro das universidades federais, que, nos últimos anos, vêm modernizando suas práticas, objetivando a melhoria da qualidade dos serviços prestados.

A gestão das pessoas nas universidades varia de acordo com a cultura institucional vigente. Para cumprir o propósito das universidades, a gestão de pessoas deve assegurar o investimento na capacitação contínua dos seus profissionais, em boas condições de trabalho e de avaliação. Em termos gerais, as universidades públicas tendem a possuir um modelo de gestão mais centralizado. Independentemente da sua configuração, as universidades devem estar atentas para que o planejamento de recursos humanos esteja integrado ao planejamento institucional. (ALBUQUERQUE, 2002). 
Para Recktenvald e Souza (2016) as relações de trabalho são complexas nas universidades, e as estimulam a criar tais normatizações, tendo em vista que os docentes das instituições federais desenvolvem atividades indissociáveis de ensino, pesquisa e extensão, além de atividades administrativas, em diferentes regimes de contratos. Essas normatizações dão origem ao PAAD.

Amparadas pela Constituição Federal (CF) de 1988, e pela Lei de Diretrizes e Bases da Educação Brasileira (LDB) (Lei nº 9.394, de 20/12/1996), as universidades públicas federais gozam de autonomia universitária, que reflete diretamente na forma como a gestão de pessoal define suas normatizações. (BRASIL, 1988; BRASIL, 1996b).

Para garantir a autonomia didático-científica das universidades, a Lei $\mathrm{n}^{\circ}$ 9.394, de 20/12/1996, Lei de Diretrizes e Bases da Educação Brasileira (LDB) orienta que cabe aos seus colegiados de ensino e pesquisa decidir, dentro dos recursos orçamentários disponíveis, sobre: criação, expansão, modificação e extinção de cursos; ampliação e diminuição de vagas; elaboração da programação dos cursos; programação das pesquisas e das atividades de extensão; contratação e dispensa de professores; e planos de carreira docente. (BRASIL, 1996).

A referida LDB estabelece ainda que os docentes tem a obrigação de participar da elaboração da proposta pedagógica do estabelecimento de ensino; elaborar e cumprir plano de trabalho, segundo a proposta pedagógica do estabelecimento de ensino; zelar pela aprendizagem dos alunos; estabelecer estratégias de recuperação para os alunos de menor rendimento; ministrar os dias letivos e horas-aula estabelecidos, além de participar integralmente dos períodos dedicados ao planejamento, à avaliação e ao desenvolvimento profissional; colaborar com as atividades de articulação da escola com as famílias e a comunidade. Além disso, o docente é obrigado a ministrar no mínimo oito horas semanais de aulas. (BRASIL, 1996).

\section{METODOLOGIA}

A presente pesquisa é classificada como qualitativa, que segundo Goldenberg (1997) não se preocupa com representatividade numérica, mas com o aprofundamento da compreensão de um grupo social, de uma organização, etc. Minayo (2001) completa que a pesquisa qualitativa trabalha com o universo de significados, motivos, aspirações, crenças, 
valores e atitudes, o que corresponde a um espaço mais profundo das relações, dos processos e dos fenômenos que não podem ser reduzidos à operacionalização de variáveis.

Quanto aos fins esta pesquisa é classificada como descritiva, pois visa demonstrar questões de determinadas populações ou fenômenos, bem como estabelecer correlações entre as variáveis e sua natureza. (VERGARA, 2013).

A pesquisa descritiva exige do investigador uma série de informações sobre o que se deseja pesquisar. Esse tipo de estudo pretende descrever os fatos e fenômenos de determinada realidade. (TRIVIÑOS, 1987). Esta pesquisa em questão busca descrever como é feita a gestão do PAAD da UFSC, destacando suas características, procedimentos, dificuldades, por meio de documentos oficias dos docentes desta universidade.

Quanto aos meios, esta pesquisa é bibliográfica e documental além de utilizar entrevistas semiestruturadas como instrumentos de coleta de dados. A pesquisa bibliográfica é feita a partir do levantamento de referências teóricas já analisadas, e publicadas por meios escritos e eletrônicos, como livros, artigos científicos, páginas de web sites. Qualquer trabalho científico inicia-se com uma pesquisa bibliográfica, que permite ao pesquisador conhecer o que já se estudou sobre o assunto. A pesquisa documental trilha os mesmos caminhos da pesquisa bibliográfica, no entanto, a última utiliza fontes constituídas por material já elaborado, constituído basicamente por livros e artigos científicos, enquanto a pesquisa documental recorre a fontes mais diversificadas e dispersas, sem tratamento analítico, tais como: tabelas estatísticas, jornais, revistas, relatórios, documentos oficiais, cartas, filmes, fotografias, pinturas, tapeçarias, relatórios de empresas, vídeos de programas de televisão, etc. (FONSECA, 2002)

A entrevista é um processo de interação social, no qual o entrevistador tem a finalidade de obter informações do entrevistado, por meio de um roteiro contendo tópicos em torno de uma problemática central. (Haguette, 1995). Para Minayo (1994) a entrevista privilegia a obtenção de informações através da fala individual, a qual revela condições estruturais, sistemas de valores, normas e símbolos e transmite, através de um porta-voz, representações de determinados grupos. Optou-se pela entrevista semiestruturada, na qual o informante tem a possibilidade de discorrer sobre suas experiências, a partir do foco principal proposto pelo pesquisador; ao mesmo tempo em que permite respostas livres e espontâneas do informante, além de valorizar a atuação do entrevistador. (Triviños, 1987). 
Boni e Quaresma (2005) destacam a importância da escolha dos entrevistados, que devem ter familiaridade com o tema e a disponibilidade para a entrevista, antecipadamente agendada. $\mathrm{Na}$ presente pesquisa, foram entrevistados os responsáveis pelo PAAD na Superintendência de Governança Eletrônica e Tecnologia da Informação e Comunicação (SETIC), na Pró-Reitoria de Graduação (PROGAD), e o chefe de um dos departamentos da universidade. As entrevistas foram agendadas conforme a agenda dos entrevistados, todas no segundo semestre de 2017. As entrevistas foram gravadas com o consentimento dos sujeitos da amostra, transcritas e categorizadas conforme as respostas dos entrevistados.

Por fim essa pesquisa é classificada como estudo de caso, que pode ser caracterizado como um estudo de uma entidade bem definida como um programa, uma instituição, um sistema educativo, uma pessoa, ou uma unidade social. Visa conhecer em profundidade o como e o porquê de uma determinada situação que se supõe ser única em muitos aspectos, procurando descobrir o que há nela de mais essencial e característico. O pesquisador não pretende intervir sobre o objeto a ser estudado, mas revelá-lo tal como ele o percebe. O estudo de caso pode decorrer de acordo com uma perspectiva interpretativa, que procura compreender como é o mundo do ponto de vista dos participantes, ou uma perspectiva pragmática, que visa simplesmente apresentar uma perspectiva global, tanto quanto possível completa e coerente, do objeto de estudo a partir do ponto de vista do investigador. (FONSECA, 2002, p. 33).

Para Alves-Mazzotti (2006) os exemplos mais comuns para esse tipo de estudo são os que focalizam apenas uma unidade: um indivíduo (como os casos clínicos descritos por Freud), um pequeno grupo (como o estudo de Paul Willis sobre um grupo de rapazes da classe trabalhadora inglesa), uma instituição (como uma escola, um hospital), um programa (como o Bolsa Família), ou um evento (a eleição do diretor de uma escola).

\section{CARACTERIZAÇÃO DA UFSC}

A Universidade Federal de Santa Catarina (UFSC) foi criada com o nome de Universidade de Santa Catarina em dezembro de 1960. O primeiro reitor foi o professor João David Ferreira Lima, escolhido de lista tríplice, o qual tomou posse em 25/10/1961. A Universidade contava, então, com 847 alunos e 49 docentes provindos de sete faculdades isoladas que inicialmente a compuseram, junto com uma nova faculdade. Assim 
como outras universidades patrocinadas pela União, a UFSC ganhou a denominação de universidade federal pela Lei 4.759, de 20 de agosto de 1965. (PDI, 2010-2014).

O Estado de Santa Catarina acompanhava o país e passava por boa fase de crescimento econômico, consolidando setores industriais como o da cerâmica no sul do estado, o de papel, papelão e pasta mecânica, principalmente no Vale do Itajaí e no planalto lageano, e o de metal-mecânica no norte do estado. (PDI, 2010-2014).

O ambiente econômico era, portanto, bastante propício a demandas de expansão do ensino superior. O projeto inicial, em Santa Catarina, era o de uma universidade estadual, o que foi realizado cinco anos após a criação da UFSC, por meio da Universidade para o Desenvolvimento do Estado de Santa Catarina (UDESC), hoje denominada Universidade do Estado de Santa Catarina. (PDI, 2010-2014).

A história das duas universidades pioneiras do estado esteve, portanto, interligada desde o início. No ensino básico, o Colégio de Aplicação da UFSC foi criado em 1961 e atende ao ensino fundamental e médio, proporcionando também campo de estágio supervisionado e de pesquisa para alunos e professores da UFSC e de outras instituições públicas. (PDI, 2010-2014).

Com a reforma universitária de 1969 (Decreto 64.824, de 15/07/1969), a universidade adquiriu a estrutura administrativa atual. As faculdades deram lugar às unidades universitárias, com a denominação de centros, os quais agregam os departamentos.

De acordo com o site oficial da UFSC (2017) atualmente sua comunidade é constituída por cerca de 50 mil pessoas, entre docentes, técnicos-administrativos em educação e estudantes. São aproximadamente 5.500 professores e técnicos que atuam em atividades cujos resultados são referência no Brasil e exterior. É uma universidade pública e gratuita, e possui campi na capital catarinense e em mais quatro municípios: Araranguá, Curitibanos, Joinville e Blumenau. Todos os novos campi foram instituídos com recursos do Programa de Apoio a Planos de Reestruturação e Expansão das Universidades Federais (Reuni) do Ministério da Educação (MEC), em um processo de interiorização da universidade para outras regiões em Santa Catarina. 


\subsection{O SISTEMA PAAD UFSC}

O Plano de Atividades do Departamento (PAD) é o instrumento de planejamento semestral das atividades de ensino, de pesquisa, de extensão, de formação e de administração a serem realizadas pelos docentes nele lotados. O sistema PAAD UFSC possui normas de acordo com a Resolução $\mathrm{n}^{\circ}$ 053/CEPE/9531 de agosto de 1995.

Assim, cabe ressaltar de forma ordenada as etapas do Plano de Atividades do Departamento (PAD). Inicialmente, antes da aprovação do $\mathrm{PAD}$, o departamento procederá à elaboração do Relatório das atividades do Departamento (RAD), tais atividades referem-se às que foram desenvolvidas no último semestre concluído, com base no PAD correspondente.

O RAD tem como função subsidiar a elaboração do PAD a ser aprovado para o semestre subsequente. Este relatório, referente ao último semestre concluído será anexado ao PAD. O PAD e o RAD serão elaborados de acordo com as normas estabelecidas na resolução n ${ }^{\circ}$ 053/CEPE/9531 de agosto de 1995, originários da Pró-Reitoria de Ensino de Graduação (PREG).

Nesta etapa, os docentes devem encaminhar o PAD ao colegiado do departamento até o dia 30 de maio, até dia 15 de junho ao conselho departamental e até 30 de junho à PREG, referente ao plano do segundo semestre. Já em relação ao primeiro semestre, até 14 de novembro ao colegiado do departamento, até 30 de novembro ao conselho departamental e até 5 de dezembro à PREG.

A elaboração do PAD será coordenada pelo chefe do departamento. Dessa forma, o chefe do departamento designará uma comissão composta por três docentes para analisar e emitir parecer sobre o PAD a ser apreciado pelo colegiado. Após aprovado pelo colegiado do departamento, o PAD será encaminhado ao diretor do centro para apreciação pelo conselho departamental.

O presidente do conselho departamental designará relator ou comissão relatora para analisar e emitir parecer sobre o PAD. Após aprovado pelo conselho departamental, o PAD será encaminhado à Pró-reitoria de Ensino de Graduação para verificação da compatibilidade legal, dando-se, logo após, ciência ao departamento. A consolidação do PAD deverá ser efetuada pelo departamento após o início do semestre letivo e será apreciada pelo colegiado do mesmo e respectivo conselho departamental, num prazo máximo de 45 (quarenta e cinco) dias do seu início, sendo enviado à PREG para verificação. 
Na consolidação do PAD deverão constar as seguintes informações:

a) Número de horas destinadas às atividades de magistério superior por docente;

b) Descriminação das turmas e horário de funcionamento das disciplinas sob responsabilidade de cada docente.

Cada docente, antecedendo à elaboração do RAD, deverá encaminhar ao departamento o seu relatório Individual de Atividades (RIA) referente ao semestre anterior e antecedendo à elaboração do PAD, deverá encaminhar ao departamento o seu Plano Individual de Atividades (PIA) referente ao semestre seguinte.

O PIA e o RIA são elaborados de acordo com as normas estabelecidas na resolução ${ }^{\circ}{ }^{\circ}$ 053/CEPE/9531 de agosto de 1995, em formulários próprios, originários da Prograd. O acompanhamento e a avaliação das atividades desenvolvidas pelo docente serão realizados pelo departamento envolvido e pelos órgãos superiores competentes.

Mas afinal, quais as atividades consideradas de magistério superior? Ainda de acordo com a resolução $\mathrm{n}^{\circ}$ 053/CEPE/9531 de agosto de 1995 são consideradas as atividades a seguir:

I - ensino, pesquisa e extensão que, indissociáveis, visem à produção, à transmissão e à socialização do saber;

II - formação, objetivando a qualificação do docente para o pleno desenvolvimento;

III - administração universitária, que viabilize a operacionalização das atividades da instituição.

Entende-se por atividades de ensino:

I - a ministração de aulas em cursos de graduação, de pós-graduação, "stricto sensu" e de pós graduação "lato sensu" (especialização) permanentes, mantidos pela própria UFSC;

II - a preparação das atividades, bem como o acompanhamento e a avaliação das atividades discentes;

III - a participação no planejamento, na organização, na execução e na avaliação referentes ao ensino do departamento;

IV - a orientação e a supervisão de estágios curriculares em curso de graduação;

V - a orientação de trabalhos de conclusão de cursos de graduação;

VI - a orientação de monografias de cursos de pós graduação, "lato sensu";

VII - a orientação de dissertações de mestrado e teses doutorado nos programas de pós-graduação "stricto sensu". 
Já para o cômputo da carga de ensino do docente, no Plano de Atividades do Departamento (PAD), serão utilizados os seguintes critérios:

I - a ministração de aulas será expressa em horas-aula, entendendo-se por horaaula a unidade de tempo dedicada ao exercício efetivo de aulas teóricas, práticas, de laboratório e de campo;

II - cada hora-aula dará direito ao docente a estabelecer até uma hora e meia para as atividades relativas discentes;

III - a orientação e a supervisão de estágios curriculares de curso de graduação corresponderão a 01 hora-aula por semana e por aluno.

IV - até 01 hora por semana e por aluno, nas orientações de monografias em cursos de especialização e nos trabalhos de conclusão de curso de graduação, excluídos os benefícios previstos no inciso II deste artigo;

$\mathrm{V}$ - até 02 horas por semana e por aluno, nas orientações de teses de doutoramento e nas dissertações de mestrado.

Semestralmente, o docente dará ciência ao departamento e a seus alunos dos horários destinados à orientação e ao acompanhamento das atividades discentes. Cabe às coordenadorias dos cursos de pós-graduação enviar aos departamentos, semestralmente, a relação de orientandos de cada docente, especificando a natureza desta orientação bem como sua data de início.

O docente no regime de dedicação exclusiva, ou no exercício temporário em 40 horas semanais, ministrará, no mínimo, a média anual de 8 horas-aula semanais. $\mathrm{O}$ docente, quando em atividades exclusivamente de ensino, ministrará a média anual mínima de 16 horas-aula semanais, quando em atividade exclusivamente de ensino, poderá ser atribuída carga superior a 16 horas-aula semanais, desde que com a sua aquiescência.

Os docentes ocupantes de cargos administrativos, com carga de 40 horas semanais, estão liberados de ministrar aulas, à disto e do afastamento para a formação em tempo integral, nenhum docente poderá deixar de ministrar aulas. Já o docente em regime de tempo parcial, ministrará no mínimo 8 horas-aulas semanais.

Caberá ao departamento efetuar a distribuição das atividades de ensino aos seus docentes. É principio da UFSC que todo docente ministre aulas em curso de graduação, sendo admitido, excepcionalmente, mediante justificativa circunstanciada no PAD, apreciada pelo CTE/PREG, que o docente ministre, temporariamente, aulas apenas em cursos de pósgraduação. 
Um docente universitário exerce atividade de pesquisa e extensão. Entende-se por atividades de pesquisa a execução de projetos que visem à produção e à ampliação do saber. A forma de proposição e os critérios de apreciação de atividades de pesquisa, assim como as regras para o seu acompanhamento e para a avaliação de sua execução, terão definição em normas específicas do CEPE. As atividades de pesquisa deverão constar do PAD e não poderão exceder, em média anual, a 20 horas semanais, por docente.

Entende-se por atividades de extensão a execução de projetos que visem a interação sistematizada com a sociedade, a ministração de cursos de especialização, de aperfeiçoamento ou de outros cursos de curta duração. A forma de proposição e os critérios de apreciação de atividades de extensão, assim como as regras para o seu acompanhamento e para a avaliação de sua execução, terão definição em normas específicas do CEPE. As atividades de extensão deverão constar do PAD e não poderão exceder, em média anual, a 20 horas semanais, por docente.

As atividades de extensão do docente, quando remuneradas, não poderão ultrapassar, no semestre, a média de 8 horas semanais.

Para se ter acesso e controle ao sistema PAAD, basta entrar na página da Universidade Federal de Santa Catarina com o endereço paad.sistemas.ufsc.br, o qual pode ser acessado por toda a comunidade. Nesta página, há o controle por atividades que cada professor realiza dentro do seu departamento. A seguir serão apresentados, através de uma análise, o PAAD, com imagens referentes ao Departamento de Ciências da Administração e seus professores.

Ao acessar o site, deve-se escolher o centro e departamento do qual se pretende analisar o PAAD. Observa-se um sinal verde em alguns departamentos, isso significa que tal departamento obteve aprovação, seja do departamento, centro ou DCN (Diretrizes Curriculares Nacionais), como apresentado na Figura 1.

Ao clicar no departamento escolhido, neste caso, o Departamento de Ciências da Administração, encontra-se o PAAD de todos os professores pertencentes àquele departamento e as horas em cada atividade realizadas por cada docente, como apresentado na Figura 2. 


\section{GESTÃO DO PLANEJAMENTO E ACOMPANHAMENTO DE ATIVIDADES DOCENTES DE UMA \\ UNIVERSIDADE FEDERAL \\ DOI: http://dx.doi.org/10.5007/1983-4535.2019v12n1p118}

Figura 1 Acesso aos centros e departamentos da UFSC

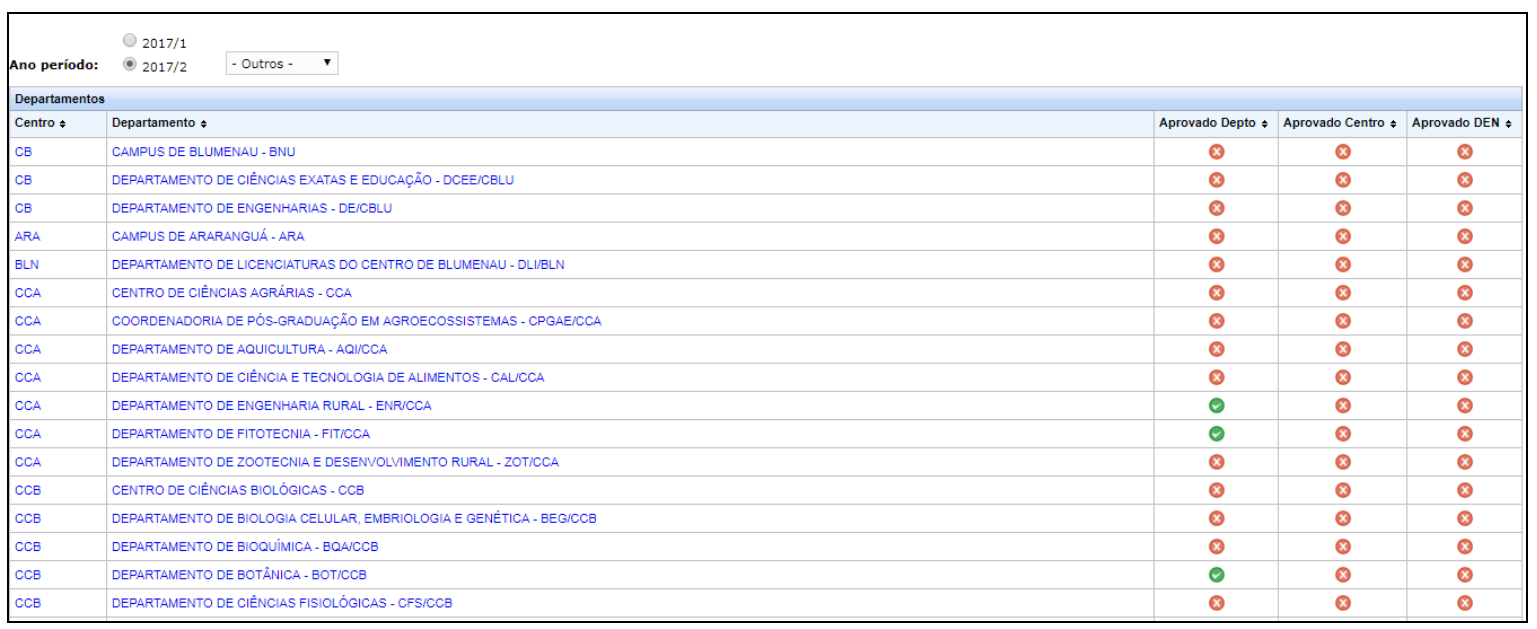

Fonte: PAAD UFSC (2017) - paad.sistemas.ufsc.br

Figura 2 lista de professores e carga horárias em cada atividade docente no PAAD

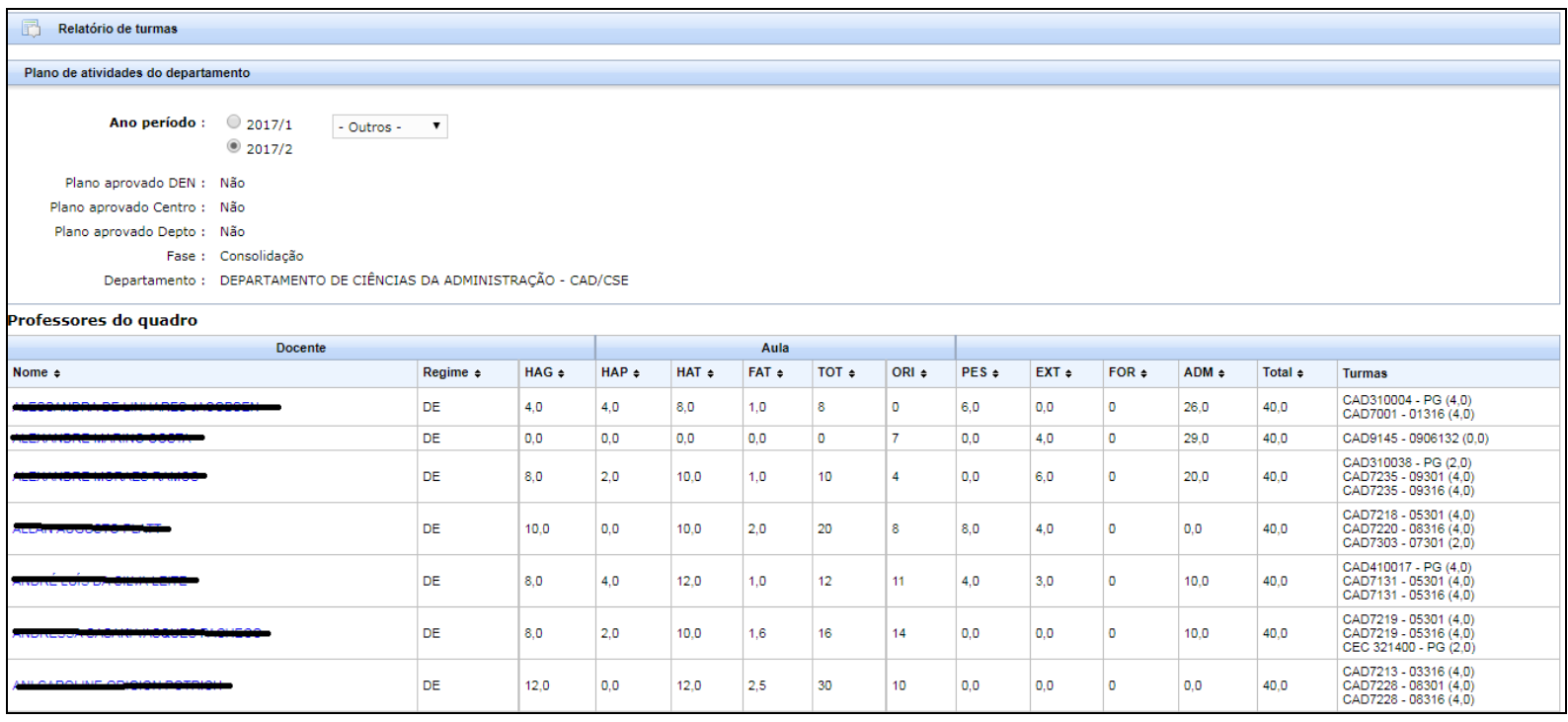

Fonte: PAAD UFSC (2017) - paad.sistemas.ufsc.br

Ao clicar no nome de um professor em especifico, obtém-se detalhes sobre as atividades realizadas naquele semestre, como datas e carga horária dedicada a ensino, pesquisa, extensão, orientações, administração e formação. Conforme apresentado na Figura 3. 
Figura 3 PAAD individual do docente

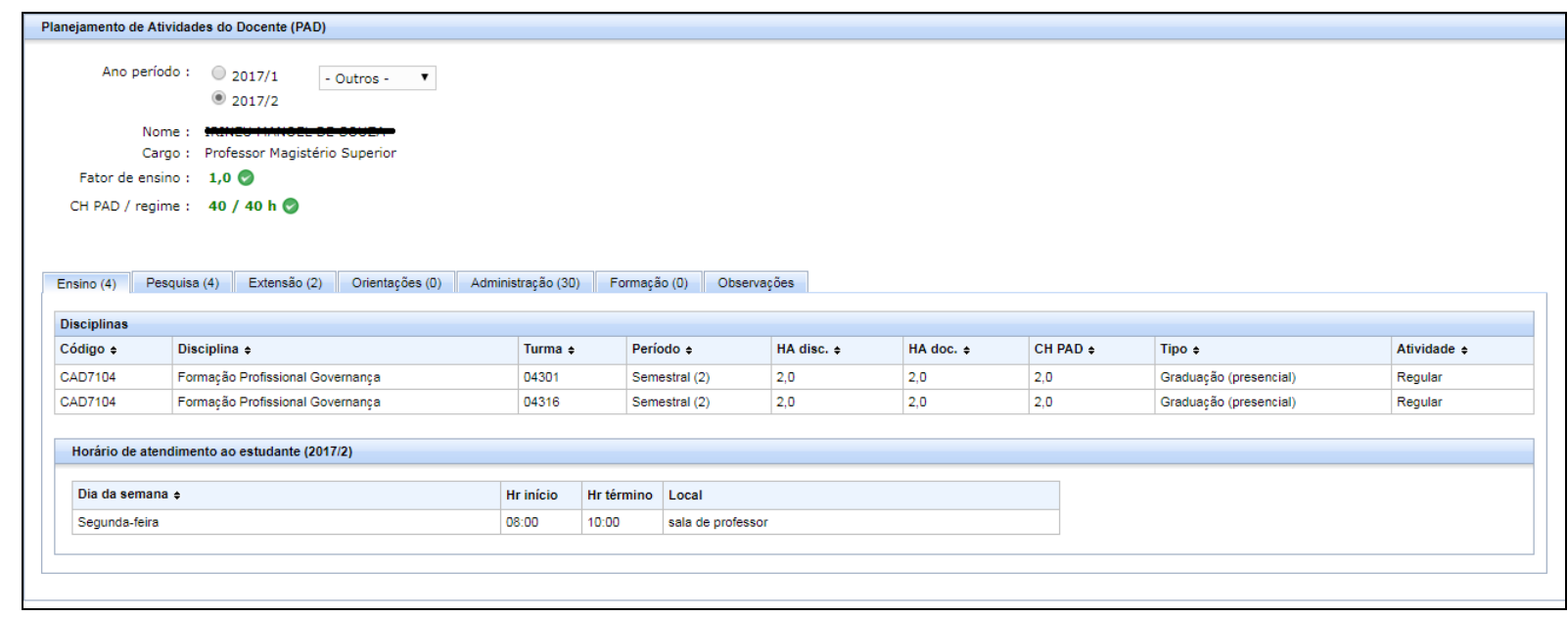

Fonte: PAAD UFSC (2017) - paad.sistemas.ufsc.br

Mas será que o sistema PAAD retrata fielmente a realidade dos docentes universitários da UFSC? Todos realizam exatamente as atividades e cargas horárias presentes no sistema? Levando em conta que o PAAD significa um planejamento das atividades, por meio das entrevistas semiestruturadas constataram-se alguns pontos:

Segundo o responsável pela Setic-UFSC o principal fator para o funcionamento do PAAD são as informações fornecidas pelos docentes em seus departamentos. Em relação ao programa e suas vantagens, acredita-se que o programa tornam públicas as atividades docentes, permitindo certa fiscalização pela comunidade universitária. Por outro lado, o programa não retrata fielmente a realidade dos fatos, já que um controle exato das atividades dos professores de cada departamento seria quase impossível, levando em conta que o que está registrado no PAAD pode mudar durante o semestre.

Além disso, o entrevistado acrescenta que ao limitar no sistema a carga horária dos docentes, o PAAD pode causar a omissão, ou preenchimento de horas em atividades que não existem. Por fim o responsável pela Setic-UFSC acredita que devam ser feitas melhorias, uma vez que, em sua opinião, faltam informações gerenciais no sistema, além da ausência de um relatório realizado, limitando-se ao planejamento.

Conforme a responsável pelo PAAD na Prograd, o sistema está em constantes mudanças e melhorias, totalmente sistematizado para atender a resolução $n{ }^{\circ}$ 053/CEPE/9531, já citada anteriormente. A entrevistada informou que o funcionamento do planejamento das atividades docentes se dá por etapas, e após o início de cada semestre, o sistema fica aberto 
por 45 dias para edição de eventuais casos, como afastamento de docentes. Tais alterações são de responsabilidade de cada departamento.

Em seu ponto de vista, as vantagens do planejamento para a Pró-Reitoria estão relacionadas ao remanejamento de docentes nos centros e departamento, pois há o controle sobre os docentes em atividades, número de alunos por turmas, entre outras situações que o sistema ajuda a controlar, evitando que algum departamento fique sem professores, por exemplo. Para ela, as desvantagens estão relacionadas ao controle das atividades docentes retratadas pelo $\mathrm{PAAD}$, pois algumas situações não são preenchidas automaticamente pelo programa, necessitando de alteração pelo próprio docente, chefe de departamento ou diretor do centro.

Ainda para esta entrevistada, o programa requer melhorias, mas já avançou muito nos últimos anos. Ela acredita que o controle absoluto é impossível, mas que cada departamento deve fazer o controle das atividades realizadas pelos seus docentes e repassar com o máximo de clareza à Prograd. Por fim, cita que deveria ser implantado um sistema de emissão de portarias automático para as atividades realizadas pelos docentes, pois é uma função trabalhosa e pouco prática aos mesmos.

De acordo com o Chefe de Departamento de um curso, antes de registrar no PAAD as informações docentes, é criado por ele uma planilha no excel com todas as atividades que os professores realizam, para ter-se um controle mais real das funções docentes. Em sua opinião, é de responsabilidade do departamento o controle das atividades dos professores: se estão afastados, em sala de aula, e realizando outras atividades relacionadas à pesquisa e extensão ou administrativa.

Para o chefe do departamento as vantagens estão relacionadas à organização das atividades docentes, e a respeito da visualização que os professores podem ter ao se relacionarem com o PAAD, como por exemplo, enxergar a complexidade de alocar professores em sala de aula e dessa forma entender e colaborar com o problema. Porém o sistema é um pouco falho, pois depende da atualização correta de outros sistemas, como o Sistema de Controle Acadêmico de Graduação - CAGR-UFSC, para que o PAAD apareça corretamente, o que muitas vezes acarreta em erros, pois o sistema confunde os dados e informações.

O entrevistado relatou ainda que depois de um período em aberto, não é possível realizar alterações no sistema, e para atualizar as mudanças que ocorrem constantemente na 
vida acadêmica dos docentes, é preciso fazer observações no sistema PAAD, em um espaço reservado para isso, já que as mudanças em horas e atividades não podem ser feitas diretamente.

Para ele a alimentação do sistema deveria ser melhorada, pois em muitos itens é feita manualmente, exigindo controle e fiscalização por parte dos docentes e do próprio departamento. Outro ponto para melhorias é aumentar o conhecimento e visão que os docentes têm do sistema, pois para muitos a complexidade desse não dá clareza.

\section{CONCLUSÃO}

Por meio do estudo feito no PAAD-UFSC constatou-se que este planejamento está direcionado para atender a resolução n ${ }^{\circ}$ 053/CEPE/9531 de agosto de 1995. Através do estudo de tal resolução, verificação do sistema de forma virtual, e entrevistas com responsáveis pelo planejamento das atividades docentes da Universidade Federal de Santa Catarina, conheceu-se as complexidades e desafios de tal sistema. Por meio de observações, constatou-se que o sistema transmite o que cada professor planeja fazer no decorrer dos semestres, além das horas dedicadas em cada atividade, deixando claro sua função como docente.

Já por meio das entrevistas, observou-se que o sistema pode não transmitir claramente a realidade dos docentes, pois além de mudanças constantes acontecerem no decorrer do semestre, como afastamentos, conclusão de alguma orientação entre outras, o sistema limita as horas que um docente pode dedicar-se às funções, fazendo com que muitas vezes os professores omitam horas dedicadas ao trabalho ou preencham horas faltantes.

As principais sugestões de melhorias e aprimoramento do sistema estão relacionadas à praticidade, pois algumas situações precisam ser preenchidas manualmente ou dependem de outros sistemas, fazendo com que algumas falhas aconteçam. Outra sugestão seria a inclusão de um sistema de emissão de portarias, pois como os professores realizam diversas atividades externas, facilitaria o processo de inclusão desses documentos no sistema, que hoje é também preenchido de forma manual.

Por fim, poderia ser criado um espaço, dentro do próprio sistema PAAD, com as atividades docentes realizadas. Como o planejamento só pode ser alterado no prazo de 45 dias, este espaço teria função de transmitir a realidade com mais clareza, visto que no decorrer dos semestres muitas mudanças ocorrem, como o término de uma orientação, um imprevisto que 
afaste o docente de suas atividades, entre outras situações. Enfim, se teria uma noção exata e confiável do planejado e o realizado.

\section{REFERÊNCIAS}

ALBUQUERQUE, L. G. de. A gestão estratégica de pessoas. In: FLEURY, M. T. L. (Coord.) As pessoas na organização. São Paulo: Editora Gente, 2002, p. 35-50.

ALMEIDA, Mario de Souza. Elaboração de Projeto, TCC, Dissertação e Tese. $1^{\text {a }}$ ed. São Paulo. Atlas, 2011.

ARANHA, J.G.T; SALLES, D.M.R. A evolução da Gestão de Pessoas nas Universidades Federais: do patrimonialismo ao estratégico - CIGU Desafios da Gestão Universitária no Século XXI Mar del Plata - Argentina 2, 3 e 4 de dezembro de 2015.

ALVES-MAZZOTTI, A. J.; GEWANDSZNAJDER, F. O método nas ciências naturais e sociais: pesquisa quantitativa e qualitativa. São Paulo: Pioneira, 1998.

BRASIL. Constituição (1988). Constituição da República Federativa do Brasil. 29 ed. atual. e ampl. São Paulo: Saraiva, 2002.

BORGES, Djalma Freire; ARAÚJO, Maria Arlete Duarte. Uma experiência de planejamento estratégico em universidade: o caso do centro de ciências sociais aplicadas da UFRN. Revista de Administração Pública. FGV. Rio de Janeiro 35 (4) 63-76 jul/ago 2001.

BOBBIO, Norberto. Estado, Governo e Sociedade: para uma teoria geral da política. $9^{\mathrm{a}}$ ed. São Paulo: paz e terra, 2001.

BONI, Valdete; QUARESMA, Silvia Jurema. Aprendendo a entrevistar: como fazer entrevistas em ciências sociais. Em tese, Florianópolis, v. 2, n.1, p. 68-80, jan., 2005.

BRASIL. Lei n 9.394, de 20 de dezembro de 1996. (1996) Disponível em: $<$ http://www.planalto.gov.br/ccivil_03/leis/19394.htm> Acesso em 22 de julho de 2017.

BÚRIGO, Carla Cristina Dutra. O trabalho acadêmico do professor universitário no processo de desenvolvimento do espaço público na Universidade Federal: um estudo de caso na Universidade Federal de Santa Catarina e na Universidade Federal do Rio Grande do Sul. Porto Alegre, 2003.

Estrutura UFSC. Disponível em $<$ http://estrutura.ufsc.br/ $>$ Acessado em: 15 de agosto de 2017.

FOLLE, A. et al. Construção da Carreira Docente em Educação Física: Escolhas, Trajetórias e Perspectivas. Red de Revistas Científicas de América Latina y el Caribe, España y Portugal, Porto Alegre, v. 15, n. 01, p. 25-49, janeiro/março de 2009. 
GIRARD, Dante et al. Considerações sobre a importância da aplicação da teoria dos Sistemas nos processos de Gestão de Pessoas nas Universidades: um estudo de caso na uffs. Argentina: Bicentenario, 2010.

GOLDENBERG, M. A arte de pesquisar. Rio de Janeiro: Record, 1997.

HAGUETTE, T.M.F. Metodologias qualitativas na sociologia. 4.ed. Petrópolis: Vozes, 1995.

MINAYO, M.C de S. O desafio do Conhecimento: pesquisa qualitativa em saúde. 3. ed. São Paulo: Hucitec/Abrasco, 1994

PAAD UFSC. Disponível em < paad.sistemas.ufsc.br/> Acessado em 16 de agosto de 2017.

PALMEIRAS, J.B; SGARI, R; SZILAGYI, C.L.S. Desafios da Gestão Universitária: Competência e Desempenho: uma reflexão crítica na gestão. CIGU: Argentina, 2015.

PEREIRA, José Matias. Manual de Gestão Pública Contemporânea. $4^{\mathrm{a}}$ ed. São Paulo: editora atlas, 2012.

Plano de Desenvolvimento Institucional. Universidade Federal de Santa Catarina, 20102014.

RECKTENVALD, M; SOUZA, I.M. Normatização das Atividades Docentes nas Instituições Federais de Ensino Superior (IFES): O caso da Universidade Federal da Fronteira Sul. CIGU; Arequipa - Peru, novembro de 2015.

RIBEIRO, José Querino. Planificação educacional (planejamento escolar). R. bras. Est. Pedag., Brasília, v.86, n. 212, p. 85-93, jan./abr. 2005.

VASCONCELOS, Celso dos S. Planejamento: processo de ensino-aprendizagem e projeto político pedagógico $5^{\text {a }}$ ed. São Paulo. Liberdad, 1999.

VERGARA, S.C. Projetos e Relatórios de Pesquisa em Administração. $3^{\text {a }}$ ed. São Paulo. Atlas, 2013.

TRIVIÑOS, A. N. S. Introdução à pesquisa em ciências sociais: a pesquisa qualitativa em educação. São Paulo: Atlas, 1987. 